\title{
Comparison of Weibull parameters computation methods and analytical estimation of wind turbine capacity factor using polynomial power curve model: case study of a wind farm
}

\author{
Bharat Kumar Saxena ${ }^{*}$ and Komaragiri Venkata Subba Rao
}

\begin{abstract}
Introduction: Wind speed probability at a site has to be modeled for evaluating the energy generation potential of a wind farm. Analytical computation of wind turbine capacity factor at the planning stage of a wind farm is very crucial. Thus, the comparison of Weibull parameters estimation methods and computation of wind turbine capacity factor are the focus of this paper.

Case description: Soda wind farm used in this case study is located in the Jaisalmer district of western Rajasthan in India. Modeling of wind speed probability and power curve of wind turbines installed at Soda site were done for analytically estimating the capacity factor of wind turbine. Estimated capacity factors were then compared with the measured values of wind farm for validation of results.

Discussion and evaluation: Four numerical methods namely graphical, empirical, modified maximum likelihood, and energy pattern factor were used for month-wise Weibull parameters estimation at hub height of $65 \mathrm{~m}$. Power curve of the wind turbine installed at site was modeled using eighth-degree polynomial. Coefficients of polynomial were calculated from the combined use of linear least square method and QR decomposition using Gram-Schmidt orthogonalization method.

Conclusions: Results show that the percentage error in annual capacity factor estimation using Weibull parameters estimated from graphical, empirical, modified maximum likelihood, and energy pattern factor methods were $+9.98 \%,-1.59 \%,-1.22 \%$, and $-1.29 \%$, respectively. Annual capacity factor that was estimated using the Weibull parameters calculated from modified maximum likelihood method matched best with the measured values. Graphical method gave the most erroneous results.
\end{abstract}

Keywords: Weibull parameters; Frequency distribution; Wind turbine; Capacity factor; Power curve

\section{Background}

Wind power of a site changes with the change in seasons and thus affects the capacity factor of wind turbines. Wind speed distribution at hub height has to be month-wise modeled for estimating the influence of atmospheric parameters on wind power. Wind speed probability modeling and estimation of wind turbine capacity factor for a site are investigated by many researchers. Jangamshetti \& Rau $(1999,2001)$ used normalized power curves as a tool

\footnotetext{
* Correspondence: bkumarsin@yahoo.com

Centre for Energy and Environment, Rajasthan Technical University, Kota 324010, India
}

for identification of optimum wind turbine generator parameters. Rehman and Ahmad (2004) analyzed wind data for five coastal locations. Rocha et al. (2012) explained the analysis and comparison of seven numerical methods for finding the parameters for Weibull probability distribution. Jowder (2009) presented the statistical study of wind speed and power at various heights. EL-Shimy (2010) studied the problem of site matching of wind turbine generator through improved formulation of capacity factor. Huang and Wan $(2011,2012)$ determined a modular approach to enhance capacity factor computation of wind turbine generators. Albadi and El-Saadany $(2009,2010,2012)$ 
proposed a novel method for estimating the capacity factor of variable speed wind turbines. Chang et al. (2003) investigated and compared monthly wind characteristics and monthly wind turbine characteristics for four meteorological stations with high winds. Chang and Tu (2007) analyzed monthly energy output and monthly capacity factor of a wind farm. Ditkovich et al. (2012) proposed a method for estimating capacity factor for stall and pitchregulated wind turbines. $\mathrm{Hu}$ and Cheng (2007) presented a method for determining sites and wind turbine generator pairing.

This paper presents the month-wise graphical comparison between measured wind speed frequency and Weibull wind speed probabilities estimated using four numerical methods. It also uses a polynomial of eighth degree for modeling wind turbine power curve. A method for estimating the $n$th degree polynomial coefficients of wind turbine power curve with combined use of linear least square and QR decomposition using Gram-Schmidt orthogonalization through MATLAB is also presented. Coefficients of eighth-degree polynomial are used in the capacity factor estimation from generic model given by Albadi (2010). Estimated capacity factors are compared with the measured capacity factor of a wind turbine working at Soda site, for validation of results.

\section{Case description}

\section{Details of the wind farm studied}

Wind farm located at Soda site in the Thar desert region of western Rajasthan, India is selected for this study. It is in Jaisalmer district where May and June are hottest and January is the coldest month. Rainfall is very low and monsoon winds that bring rains in India bypass this region. Wind farm has twenty 1.25-MW capacity Suzlon-S66 turbines as shown in Figures 1 and 2. The total capacity of wind farm is $25 \mathrm{MW}$ and turbines are having hub height of $65 \mathrm{~m}$, cut-in speed $v_{c}$ of $3 \mathrm{~m} / \mathrm{s}$, rated speed $v_{r}$ of $14 \mathrm{~m} / \mathrm{s}$, and cut-off speed $v_{f}$ of $22 \mathrm{~m} / \mathrm{s}$ (http://www. suzlon.com/pdf/s66\%20product\%20brochure.pdf. Accessed 09 September 2014). Wind and meteorological data measurement mast of $65-\mathrm{m}$ height at Soda wind farm is shown in Figure 3. Its specific position in the wind farm is marked in Figure 2.

\section{Wind data modeling and analysis}

Mean wind speed and standard deviation of grouped data are defined by Jangamshetti and Rau (1999), Manwell et al. (2009), and Bird (2003) as:

$$
\bar{v}=\frac{\sum_{i=1}^{n}\left(f_{m}\left(v_{i}\right) \times v_{i}\right)}{\sum_{i=1}^{n} f_{m}\left(v_{i}\right)}
$$

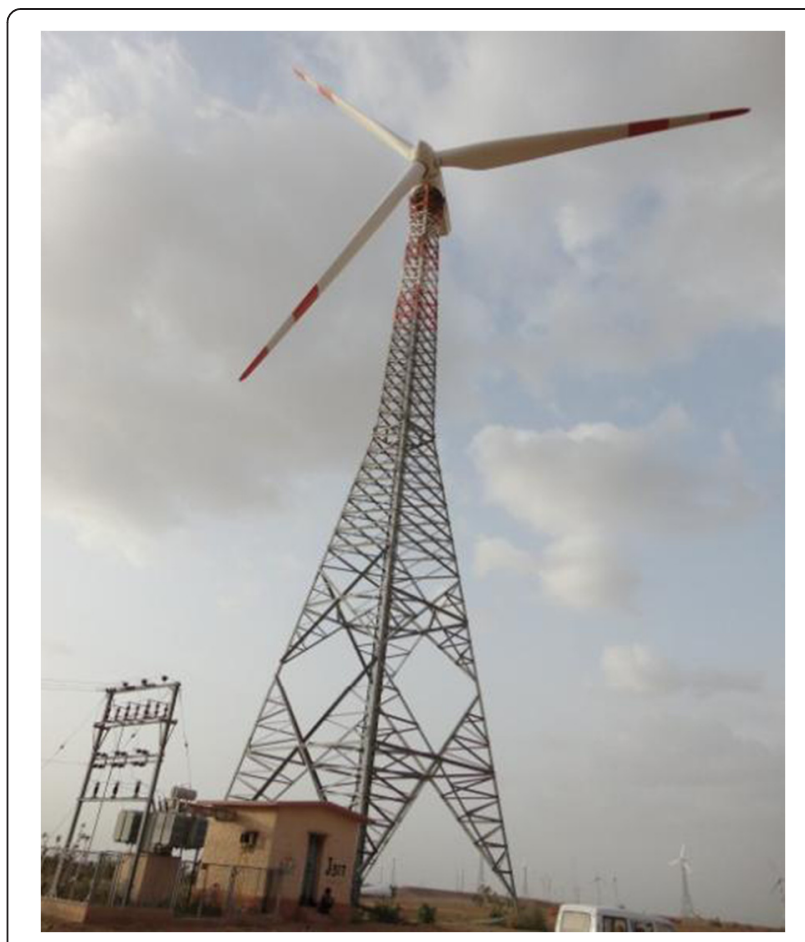

Figure 1 Suzlon S- 66 wind turbine of $1.25 \mathrm{MW}$ at the wind farm.

$$
\sigma=\sqrt{\frac{\sum_{i=1}^{n} f_{m}\left(v_{i}\right) \cdot\left(v_{i}-\bar{v}\right)^{2}}{\sum_{i=1}^{n} f_{m}\left(v_{i}\right)}}
$$

where $\bar{v}$ is the mean wind speed in meter per second, $\sigma$ is the standard deviation of wind speed in meter per second, $v_{i}$ is the wind speed in meter per second at $i$ th bin midpoint, $f_{m}\left(v_{i}\right)$ is the measured frequency of wind speed for $i$ th bin, and $n$ is the number of wind speed bins.

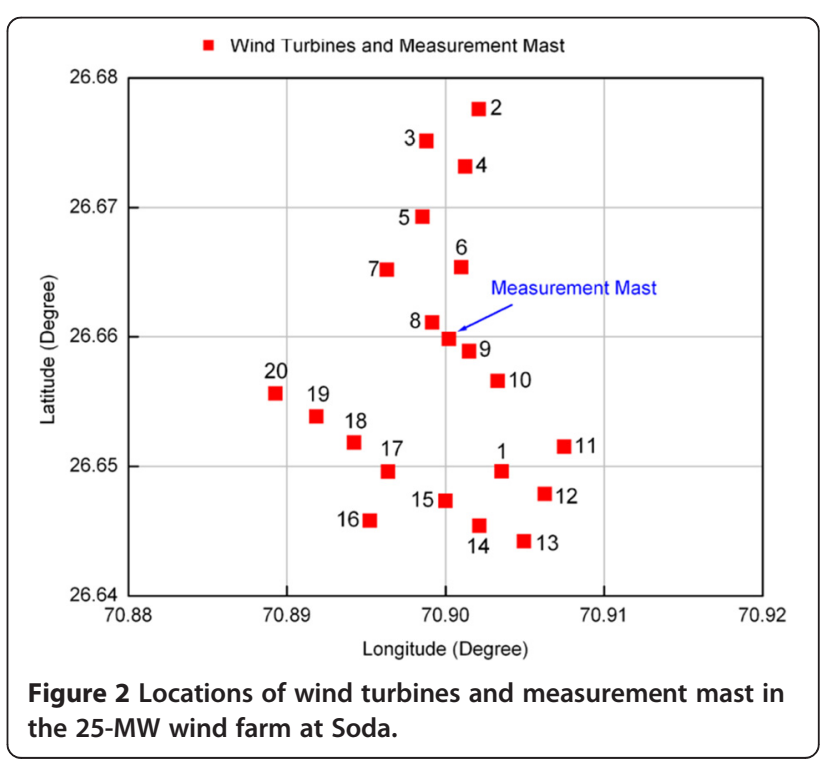




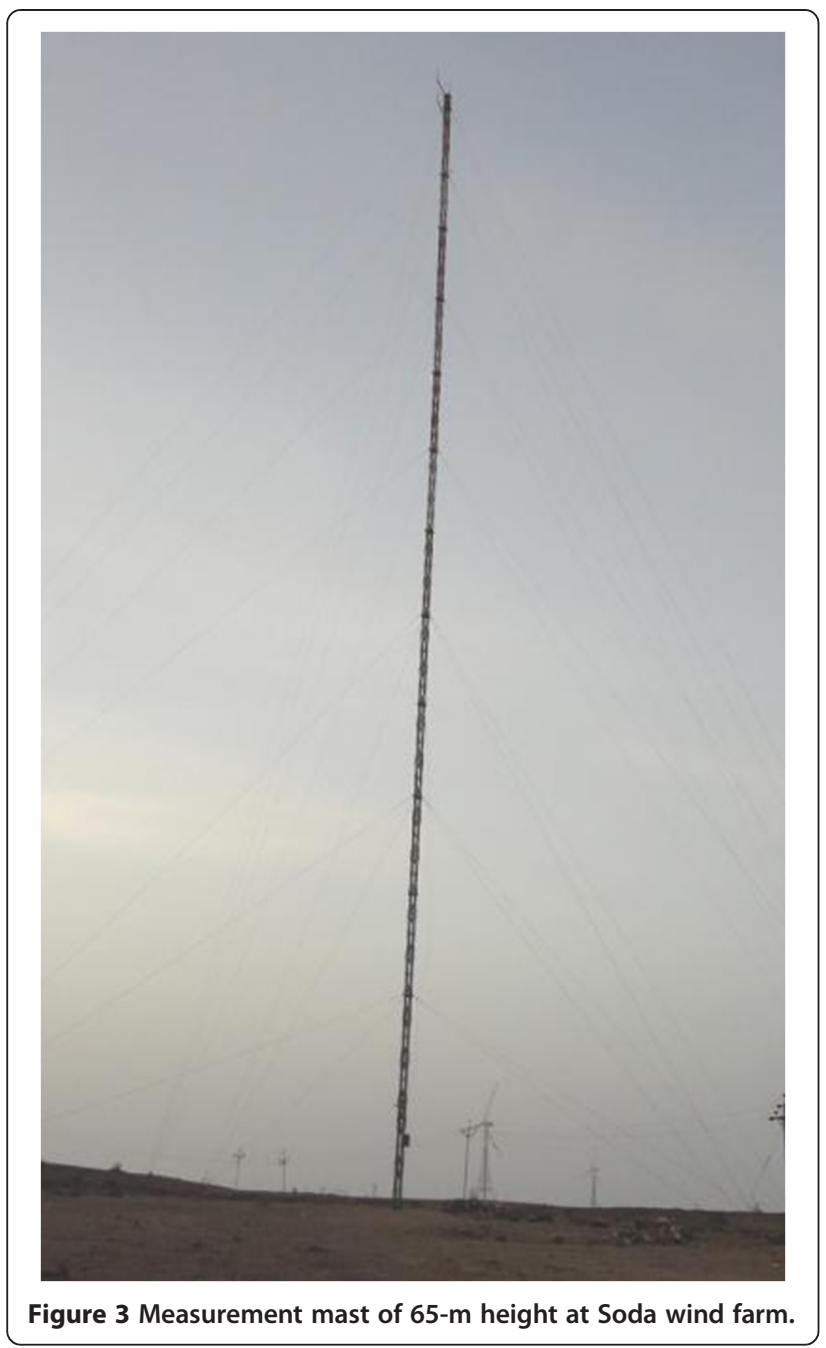

Weibull probability density function and its cumulative distribution function, used for describing the wind speed frequency distribution of a site, are defined by Masters (2004) as:

$$
\begin{aligned}
& f(v)=\frac{k}{c}\left(\frac{v}{c}\right)^{k-1} \exp \left(-\left(\frac{v}{c}\right)^{k}\right) \\
& F(v)=1-\exp \left(-\left(\frac{v}{c}\right)^{k}\right)
\end{aligned}
$$

where $f(v)$ is the Weibull wind speed probability density function at hub height, $F(v)$ is the Weibull cumulative distribution function, $v$ is the wind speed in meter per second, $k$ is the shape parameter at hub height, and $c$ is the scale parameter at hub height.

Power available in the wind $\left(P_{w}(v)\right)$ is expressed as $P_{w}(v)=0.5 \rho A v^{3}$, where $\rho$ is the air density in kilogram per cubic meter, $A$ is the rotor swept area in square meter, and $v$ is the wind speed in meter per second. Wind power density (WPD) of a site that is based on
Weibull distribution is defined by Jowder (2009), Huang and Wan (2012), and Chang et al. (2003) as:

$$
\mathrm{WPD}=\int_{0}^{\infty} P_{w}(v) f(v) d v=0.5 \rho c^{3} \Gamma(1+3 / k)
$$

where $\Gamma$ is a gamma function.

Root mean square error (RMSE) is based on the variation between measured and estimated values. RMSE of wind speed probability is defined by Rocha et al. (2012) and Bird (2003) as:

$$
\mathrm{RMSE}=\sqrt{\left[\frac{1}{n} \sum_{i=1}^{n}\left(f_{m}\left(v_{i}\right)-f_{c}\left(v_{i}\right)\right)^{2}\right]}
$$

where $f_{m}\left(v_{i}\right)$ is the measured wind speed frequency for $i$ th bin, $f_{c}\left(v_{i}\right)$ is the estimated Weibull wind speed probability, $v_{i}$ is the wind speed at $i$ th bin midpoint, and $n$ is the number of observations/bins. The percentage error between measured and estimated value is calculated using expression:

$$
\text { Error } \%=\frac{\text { measured value-estimated value }}{\text { measured value }} \times 100 \text {. }
$$

\section{Estimation of Weibull scale and shape parameters}

Graphical method (GM) (Johnson 1978) uses Weibull cumulative distribution function and least square approximation for calculating the scale and shape parameters. Using Equation 4 and on taking twice the logarithm of each side, it becomes a form of straight line equation written as $y=a x+b$ where $y=\ln [-\ln (1-F(v))], a=k, x=$ $\ln (v)$, and $b=-k \ln (c)$. For $n$ pairs of $(x, y)$ where all summations are from 1 to $n$, the values of $a$ and $b$ are expressed as:

$$
\begin{gathered}
a=\frac{\sum x y-\frac{\sum x \sum y}{n}}{\sum x^{2}-\frac{\left(\sum x\right)^{2}}{n}} \\
b=\bar{y}-a \bar{x}=\frac{1}{n} \sum y-\frac{a}{n} \sum x .
\end{gathered}
$$

Shape and scale parameters are then expressed as $k=a$ and $c=\exp (-b / k)$.

Empirical method (EM) uses shape and scale parameter defined by Jangamshetti and Rau (1999) and Rocha et al. (2012) as:

$$
k=(\sigma / \bar{v})^{-1.086}
$$




$$
c=\frac{\bar{v}}{\Gamma\left(1+\frac{1}{k}\right)} .
$$

Modified maximum likelihood (MML) method uses frequency distribution of wind speed. Shape parameter is calculated by using numerical iterations and then scale parameter is obtained by solving equation explicitly. Value of shape parameter is around 2 for majority of sites and is a good initial estimate for iterative process. Shape and scale parameters are defined by Rocha et al. (2012) as:

$$
\begin{aligned}
& k=\left[\frac{\sum_{i=1}^{n} v_{i}^{k} \ln \left(v_{i}\right) f\left(v_{i}\right)}{\sum_{i=1}^{n} v_{i}^{k} f\left(v_{i}\right)}-\frac{\sum_{i=1}^{n} \ln \left(v_{i}\right) f\left(v_{i}\right)}{f(v \geq 0)}\right]^{-1} \\
& c=\left(\frac{1}{f(v \geq 0)} \sum_{i=1}^{n} v_{i}^{k} f\left(v_{i}\right)\right)^{\frac{1}{k}}
\end{aligned}
$$

where $v_{i}$ is the wind speed at $i$ th bin midpoint, $n$ is the number of bins, $f\left(v_{i}\right)$ is the frequency of wind speed occurrence in bin $i$, and $f(v \geq 0)$ is the probability of wind speed $\geq 0$.

Energy pattern factor (EPF) is expressed as mean of the sum of cubes of all individual wind speed considered in a sample, divided by the cube of mean wind speed of sample (Centre for Wind Energy Technology 2011):

$$
\mathrm{EPF}=\frac{1}{(\bar{v})^{3}} \times\left(\sum_{i=1}^{n} v_{i}^{3} / n\right)
$$

where $v_{i}$ is the wind speed in meter per second for $i$ th observation, $n$ is the number of wind speed samples, and $\bar{v}$ is the monthly mean wind speed. The monthly wind power density (WPD) is given by:

$$
\mathrm{WPD}=0.5 \rho\left(\sum_{i=1}^{n} v_{i}^{3} / n\right)
$$

where $\rho$ is the monthly mean air density at hub height in kilogram per cubic meter. By substituting Equation 15 in Equation 14, EPF is expressed as:

$$
\mathrm{EPF}=\frac{1}{(\bar{v})^{3}} \times\left(\frac{\mathrm{WPD}}{0.5 \times \rho}\right)
$$

Shape parameter is calculated from EPF parameter using an expression defined by Rocha et al. (2012) as:

$$
k=1+\frac{3.69}{(\mathrm{EPF})^{2}}
$$

Scale parameter is then calculated by using the expression given in Equation 11.

\section{Polynomial model of power curve for pitch-regulated wind turbines}

Relation between wind turbine electric power output $\left(P_{e}(v)\right)$ and wind speed $(v)$ for pitch regulated wind turbines are defined by Albadi (2010) as:

$$
P_{e}(v)=P_{r} \times\left\{\begin{array}{l}
0, \\
P_{c i n r}(v), \\
1,
\end{array}\right.
$$

$$
\begin{array}{r}
\left(v<v_{c} \text { or } v>v_{f}\right) \\
\left(v_{c} \leq v \leq v_{r}\right) \\
\left(v_{r} \leq v \leq v_{f}\right)
\end{array}
$$

where $P_{r}$ is the rated electrical power, and $P_{\text {cinr }}(v)$ is the turbine output power as a fraction of rated power between (including) cut-in wind speed $v_{c}$ and rated wind speed $v_{r} . v_{f}$ is cut-out wind speed.

There are many generic power curve models reported in the literature for representing the non-linear region between cut-in and rated wind speed of Figure 4. These models are not accurate as they do not fit the manufacturer's power curve data and only provide an approximate model of power curve that has errors. The approach used in this paper is to use a polynomial of eighth degree to model manufacturer wind turbine power curve data between cut-in and rated wind speed region.

A function is called polynomial of $n$th degree when it is expressed in the form as

$$
P(v)=a_{0}+a_{1} v+a_{2} v^{2}+a_{3} v^{3}+\ldots+a_{n} v^{n}
$$

where $a_{0}, a_{1}, a_{2}, \ldots, a_{n}$ are the constant coefficients of polynomial function. The procedure of calculating coefficients of $n$ th-degree polynomial by combined use of linear least square and matrix factorization methods through MATLAB are explained below.

\section{Linear least square method}

Consider given $m$ sets of data $\left(x_{i}, y_{i}\right)$ where $i=1, . ., m$ and the polynomial model that is fitted to data is of $n$th degree expressed as:

$$
P(x)=a_{0}+a_{1} x+a_{2} x^{2}+a_{3} x^{3}+\ldots+a_{n} x^{n}
$$

where $a_{0}, a_{1}, a_{2}, \ldots, a_{n}$ are the coefficients that are to be found out. The $m$ sets of data and polynomial $P(x)$ are expressed in matrix form as $\boldsymbol{y}=\boldsymbol{X} \boldsymbol{\alpha}$ where:

$$
\begin{gathered}
\boldsymbol{y}=\left[\begin{array}{c}
y_{1} \\
y_{2} \\
\vdots \\
y_{m}
\end{array}\right], \\
\boldsymbol{X}_{(m, n+1)}=\left[\begin{array}{ccccc}
1 & x_{1} & x_{1}^{2} & \cdots & x_{1}^{n} \\
\vdots & \vdots & \vdots & \ddots & \vdots \\
1 & x_{m} & x_{m}^{2} & \cdots & x_{m}^{n}
\end{array}\right],
\end{gathered}
$$




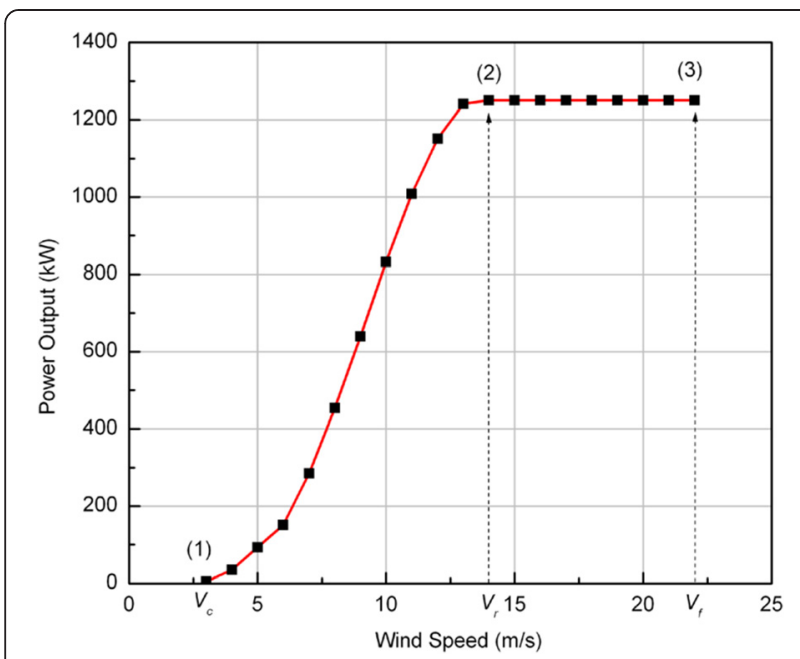

Figure 4 Power curve of Suzlon S66 1.25-MW pitch-regulated wind turbine (Wind Power Program).

$$
\boldsymbol{\alpha}=\left[\begin{array}{c}
a_{0} \\
a_{1} \\
\vdots \\
a_{n}
\end{array}\right]
$$

The coefficients $a_{0}, a_{1}, a_{2}, \ldots, a_{n}$, that best fit Equation 20 are found out by solving minimization problem, where the objective function $S$ is given by Press et al. (2009) as:

$$
S(\boldsymbol{\alpha})=\sum_{i=1}^{m}\left[\boldsymbol{y}_{i}-\sum_{j=1}^{n+1} \boldsymbol{X}_{i j} \boldsymbol{\alpha}_{j}\right]^{2}=\|\boldsymbol{y}-\boldsymbol{X} \boldsymbol{\alpha}\|^{2} .
$$

Normal equations of least square problem can be expressed in matrix notation as

$$
\left(\boldsymbol{X}^{T} \boldsymbol{X}\right) \boldsymbol{\alpha}=\boldsymbol{X}^{T} \boldsymbol{y}
$$

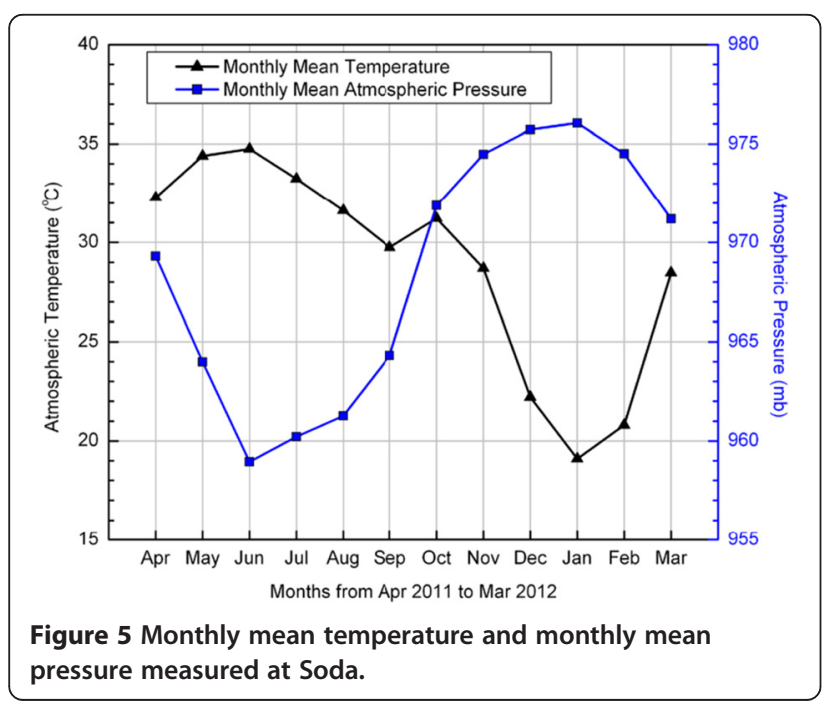

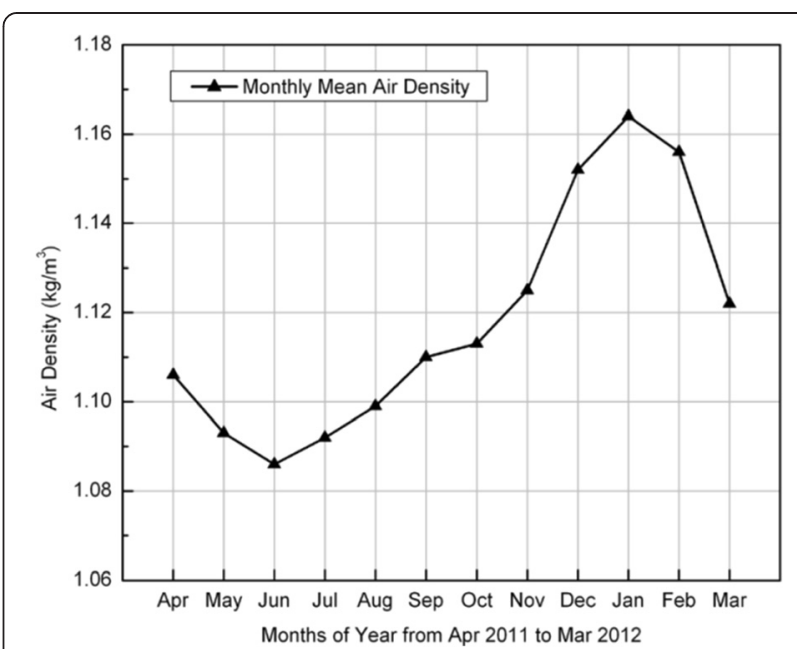

Figure 6 Monthly mean air densities at Soda wind farm.

where $\boldsymbol{X}^{T}$ is the transpose of matrix $X$. The algebraic solution of Equation 24 is expressed (Demmel 1997) as

$$
\boldsymbol{\alpha}=\left(\boldsymbol{X}^{T} \boldsymbol{X}\right)^{-1} \boldsymbol{X}^{T} \boldsymbol{y} .
$$

Solution from normal equations can have round-off errors so QR decomposition of matrix $\boldsymbol{X}$ is done.

\section{QR decomposition}

QR decomposition is a matrix factorization method (Embree 2010). It states that for any $m \times n$ matrix $X$ with $m \geq n$, there exists a unitary $m \times m$ matrix $Q$ and an upper triangular $m \times n$ matrix $\boldsymbol{R}$ such that

$$
X=Q R .
$$

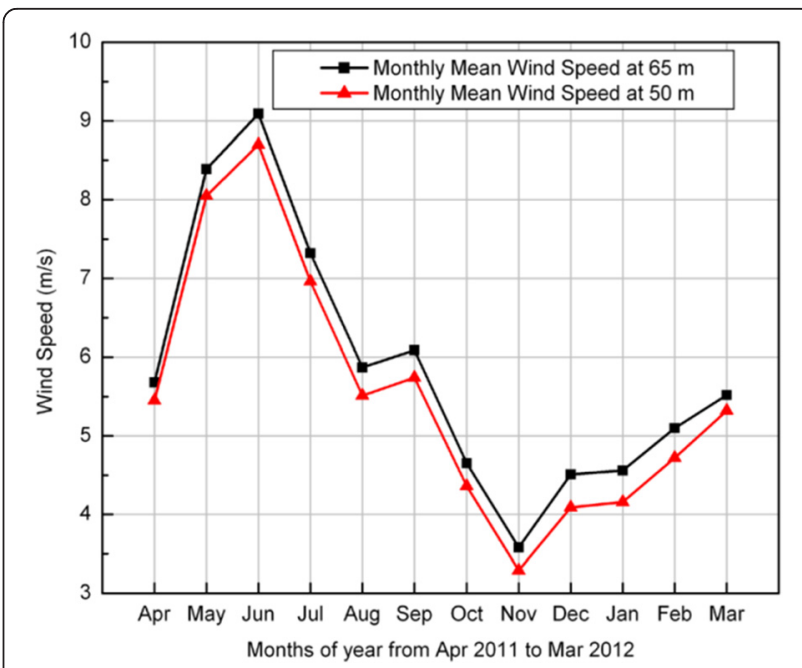

Figure 7 Monthly mean wind speed measured at $65-\mathrm{m}$ and 50-m heights. 


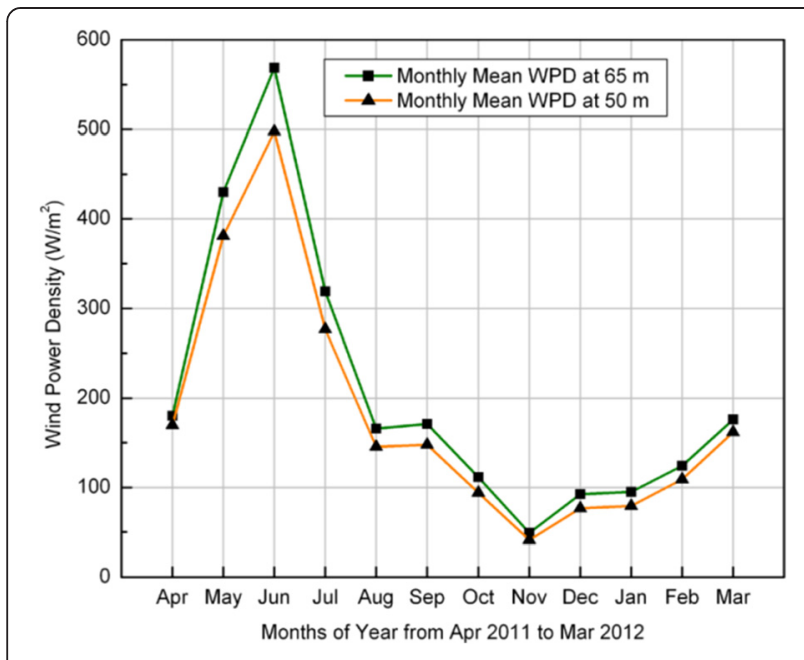

Figure 8 Monthly mean wind power density measured at $65-\mathrm{m}$ and $50-\mathrm{m}$ heights.

On substituting Equation 27 in Equation 26, the expression as explained by Demmel (1997) becomes:

$$
\begin{aligned}
& \boldsymbol{\alpha}=\left(\boldsymbol{R}^{T} \boldsymbol{Q}^{T} \boldsymbol{Q R}\right)^{-1} \boldsymbol{R}^{T} \boldsymbol{Q}^{T} \boldsymbol{y}=\left(\boldsymbol{R}^{T} \boldsymbol{R}\right)^{-1} \boldsymbol{R}^{T} \boldsymbol{Q}^{T} \boldsymbol{y} \\
& \boldsymbol{\alpha}=\boldsymbol{R}^{-1} \boldsymbol{R}^{-T} \boldsymbol{R}^{T} \boldsymbol{Q}^{T} \boldsymbol{y} \\
& \boldsymbol{\alpha}=\boldsymbol{R}^{-1} \boldsymbol{Q}^{T} \boldsymbol{y} .
\end{aligned}
$$

On solving Equation 30, the required coefficients of polynomial Equation 20 are obtained. For computing QR decomposition of matrix $\boldsymbol{X}$, the MATLAB command used is (Embree 2010):

$$
[\boldsymbol{Q}, \boldsymbol{R}]=\operatorname{qr}(\boldsymbol{X}) .
$$

This application has a $m \times n$ matrix $X$ with $m$ much larger than $n$. So, the QR decomposition produces a $m \times m$ matrix $Q$ that will require more storage than $X$ (Embree 2010). Also, columns $n+1, \ldots, m$ of $\boldsymbol{Q}$ are surplus as they multiply against zero entries of $\boldsymbol{R}$.

QR decomposition using Gram-Schmidt orthogonalization It is one solution to the above mentioned concern. This procedure results in a skinny $Q R$ decomposition, $X=Q R$, where $\boldsymbol{Q}$ is $m \times n$ matrix, $\boldsymbol{R}$ is a $n \times n$ matrix, and $\boldsymbol{Q} \boldsymbol{Q}=\boldsymbol{I}$. Here, $Q^{*}$ is the conjugate transpose matrix and $\boldsymbol{I}$ is $n \times n$ identity matrix (Embree 2010). This algorithm can be easily computed in MATLAB using command:

$$
[\boldsymbol{Q}, \boldsymbol{R}]=\operatorname{qr}(\boldsymbol{X}, \boldsymbol{O}) .
$$

If $m>n$, only the first $n$ columns of $Q$ and the first $n$ rows of $\boldsymbol{R}$ are computed (http://in.mathworks.com/help/ matlab/ref/qr.html. Accessed 09 September 2014). If $m \leq n$, then, this is same as $[\boldsymbol{Q}, \boldsymbol{R}]=\operatorname{qr}(\boldsymbol{X})$.

\section{Analytical estimation of capacity factor}

Capacity factor (CF) (Masters 2004) is defined as the ratio of average output power to rated output power over a certain period of time. Monthly capacity factor $\left(\mathrm{CF}_{\mathrm{m}}\right)$ is expressed as:

$$
\mathrm{CF}_{\mathrm{m}}=\frac{\text { monthly energy yield from wind turbine }(\mathrm{kWh})}{\text { rated power }(\mathrm{kW}) \times \text { total hours in particular month }}
$$

and the annual capacity factor $\left(\mathrm{CF}_{\mathrm{a}}\right)$ is expressed as:

\begin{tabular}{|c|c|c|c|c|c|c|c|c|}
\hline \multirow[t]{2}{*}{ Months } & \multicolumn{2}{|c|}{ Graphical method } & \multicolumn{2}{|c|}{ Empirical method } & \multicolumn{2}{|c|}{ Modified maximum likelihood method } & \multicolumn{2}{|c|}{ Energy pattern factor method } \\
\hline & $k$ & $c(m / s)$ & $k$ & $c(m / s)$ & $k$ & $c(m / s)$ & $k$ & $c(m / s)$ \\
\hline Apr 2011 & 1.7438 & 5.6863 & 2.1545 & 6.4137 & 2.0761 & 6.3507 & 2.1681 & 6.4137 \\
\hline May 2011 & 2.3472 & 9.0708 & 3.3229 & 9.3500 & 3.2595 & 9.2646 & 3.0793 & 9.3845 \\
\hline Jun 2011 & 2.0217 & 9.7378 & 2.9515 & 10.1866 & 2.9708 & 10.1471 & 2.8994 & 10.1942 \\
\hline Jul 2011 & 2.0981 & 7.7550 & 2.7184 & 8.2294 & 2.6535 & 8.1868 & 2.6637 & 8.2351 \\
\hline Aug 2011 & 1.8876 & 5.8166 & 2.6121 & 6.6079 & 2.5513 & 6.5499 & 2.6569 & 6.6044 \\
\hline Sep 2011 & 2.1592 & 6.3457 & 3.0948 & 6.8103 & 3.0623 & 6.7587 & 2.9802 & 6.8218 \\
\hline Oct 2011 & 1.5196 & 4.5302 & 1.8902 & 5.2394 & 1.7922 & 5.1967 & 1.9311 & 5.2428 \\
\hline Nov 2011 & 1.5284 & 3.4343 & 1.9543 & 4.0376 & 1.8758 & 4.0250 & 2.0225 & 4.0404 \\
\hline Dec 2011 & 1.5917 & 4.4552 & 2.1348 & 5.0925 & 2.0331 & 5.0567 & 2.2038 & 5.0924 \\
\hline Jan 2012 & 1.6794 & 4.5200 & 2.1957 & 5.1489 & 2.1198 & 5.1213 & 2.2430 & 5.1484 \\
\hline Feb 2012 & 1.8906 & 5.1810 & 2.3963 & 5.7532 & 2.3343 & 5.7274 & 2.4081 & 5.7527 \\
\hline Mar 2012 & 1.7159 & 5.6665 & 2.0785 & 6.2319 & 2.0251 & 6.2152 & 2.0626 & 6.2314 \\
\hline
\end{tabular}

$$
\mathrm{CF}_{\mathrm{a}}=\frac{\text { annual energy yield from wind turbine }(\mathrm{kWh})}{\text { rated power }(\mathrm{kW}) \times \text { total hours in a year }} \text {. }
$$

Capacity factor of a particular wind turbine at a site can be analytically estimated by using Weibull scale and shape

Table 1 Monthly Weibull parameters estimated from four numerical methods at hub height of $65 \mathrm{~m}$ 


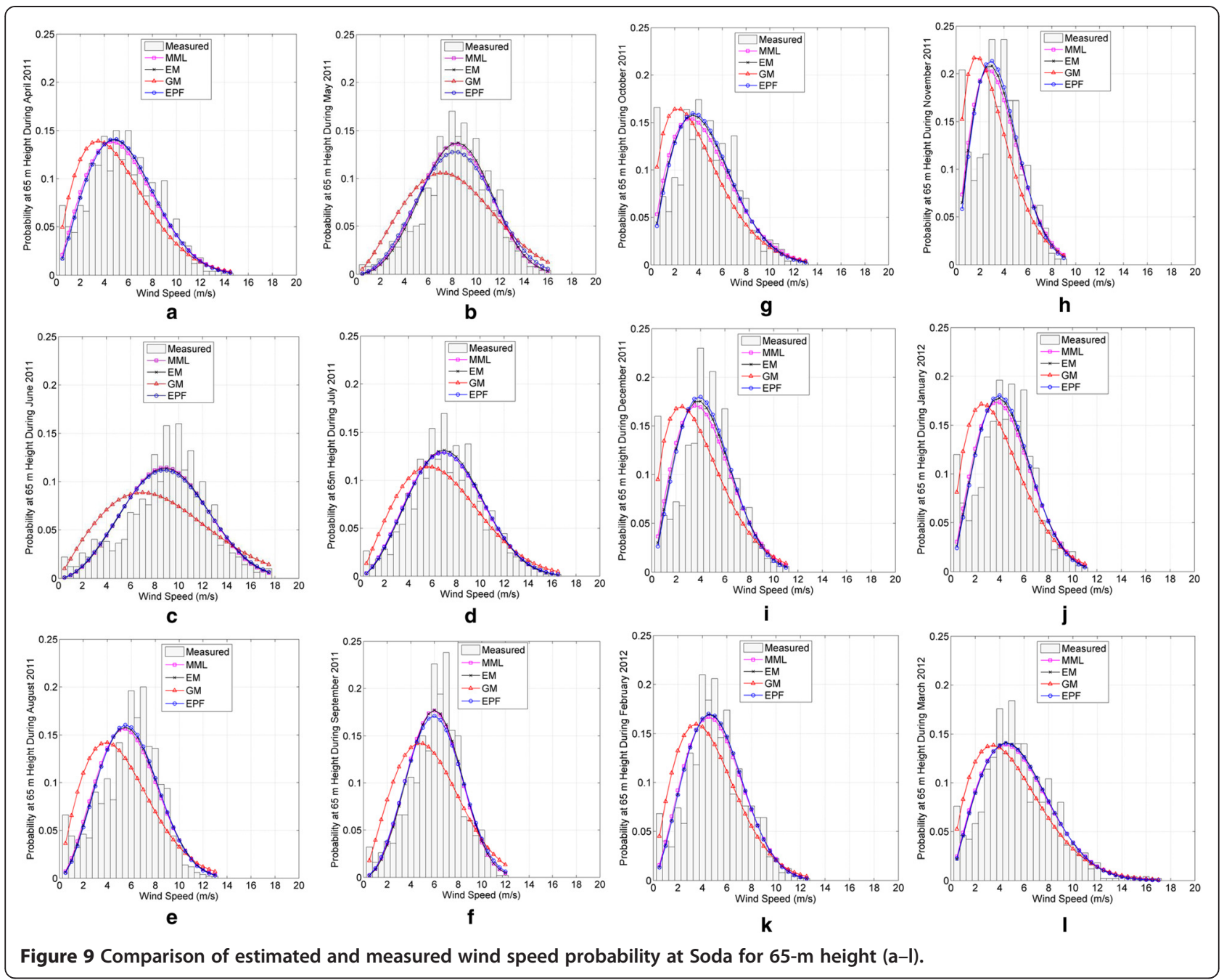

parameters of site, wind turbine speed parameters, and coefficients of polynomial model for power curve in the expression defined by Albadi (2010) as:

$$
\begin{aligned}
\mathrm{CF}=-e^{-\left(v_{f} / c\right)^{k}}+ & \sum_{i=1}^{n}\left[a_{i} \times i \times\left(c^{i} / k\right) \times \Gamma(i / k)\right. \\
& \left.\times\left(\gamma\left(\left(v_{r} / c\right)^{k}, i / k\right)-\gamma\left(\left(v_{c} / c\right)^{k}, i / k\right)\right)\right]
\end{aligned}
$$

where $\Gamma(a)=$ Gamma function $=\int_{0}^{\infty} t^{a-1} e^{-t} d t$, and $\gamma(u, a)=$ Incomplete gamma function $=[1 / \Gamma(a)] \times \int_{0}^{u} t^{a-1} e^{-t} d t$.

\section{Discussion and evaluation}

Wind and meteorological data of Soda site for the duration from April 2011 to March 2012 were provided by the owner company of wind farm. Monthly mean atmospheric pressure and monthly mean temperature at Soda
Table 2 Comparison of RMSE of wind speed probability

\begin{tabular}{lllll}
\hline Months & $\begin{array}{l}\text { Monthly } \\
\text { RMSE } \\
\text { (graphical) }\end{array}$ & $\begin{array}{l}\text { Monthly } \\
\text { RMSE } \\
\text { (empirical) }\end{array}$ & $\begin{array}{l}\text { Monthly } \\
\text { RMSE (MML) }\end{array}$ & $\begin{array}{l}\text { Monthly } \\
\text { RMSE (EPF) }\end{array}$ \\
\hline Apr 2011 & 0.0461 & 0.0443 & 0.0437 & 0.0445 \\
May 2011 & 0.0352 & 0.0399 & 0.0397 & 0.0377 \\
Jun 2011 & 0.0329 & 0.0354 & 0.0357 & 0.0350 \\
Jul 2011 & 0.0366 & 0.0387 & 0.0382 & 0.0381 \\
Aug 2011 & 0.0529 & 0.0502 & 0.0501 & 0.0507 \\
Sep 2011 & 0.0509 & 0.0530 & 0.0531 & 0.0517 \\
Oct 2011 & 0.0557 & 0.0521 & 0.0511 & 0.0527 \\
Nov 2011 & 0.0787 & 0.0737 & 0.0722 & 0.0751 \\
Dec 2011 & 0.0635 & 0.0602 & 0.0593 & 0.0611 \\
Jan 2012 & 0.0617 & 0.0583 & 0.0576 & 0.0590 \\
Feb 2012 & 0.0530 & 0.0516 & 0.0510 & 0.0518 \\
Mar 2012 & 0.0416 & 0.0402 & 0.0398 & 0.0401 \\
Average RMSE & 0.05073 & 0.04980 & 0.04929 & 0.04979 \\
\hline
\end{tabular}


Table 3 Suzlon S66-1.25-MW wind turbine power curve data (Wind Power Program; I-Rivera et al. 2009)

\begin{tabular}{|c|c|c|c|c|c|c|c|c|c|c|c|c|}
\hline Wind speed $(\mathrm{m} / \mathrm{s})$ & 3 & 4 & 5 & 6 & 7 & 8 & 9 & 10 & 11 & 12 & 13 & 14 \\
\hline Power (kW) & 5 & 35 & 93 & 151 & 285 & 454 & 639 & 832 & 1,008 & 1,152 & 1,241 & 1,250 \\
\hline Power (Normalized) y & 0.004 & 0.028 & 0.0744 & 0.1208 & 0.228 & 0.3632 & 0.5112 & 0.6656 & 0.8064 & 0.9216 & 0.9928 & 1 \\
\hline
\end{tabular}

are shown in Figure 5 and their 1-year average values are $968.49 \mathrm{mb}\left(1 \mathrm{bar}=10^{5} \mathrm{~Pa}\right)$ and $28.88^{\circ} \mathrm{C}$, respectively. Monthly mean air density based on measured temperature and pressure data is shown in Figure 6 and its 1-year average value is $1.118 \mathrm{~kg} / \mathrm{m}^{3}$.

Monthly mean wind speed at $65-\mathrm{m}$ and $50-\mathrm{m}$ heights are shown in Figure 7 and their 1-year average values are $5.86 \mathrm{~m} / \mathrm{s}$ and $5.53 \mathrm{~m} / \mathrm{s}$, respectively. Monthly mean wind power density at $65-\mathrm{m}$ and $50-\mathrm{m}$ heights are shown in Figure 8 and their 1-year average values are $206.87 \mathrm{~W} / \mathrm{m}^{2}$ and $181.71 \mathrm{~W} / \mathrm{m}^{2}$, respectively.

\section{Estimation of monthly Weibull function parameters for Soda site}

Table 1 shows the monthly Weibull parameters estimated from graphical, empirical, modified maximum likelihood, and energy pattern factor methods for Soda at height of $65 \mathrm{~m}$.

\section{Graphical comparison of measured and estimated wind speed probability}

Figure $9 \mathrm{a}-\mathrm{l}$ shows the month-wise wind speed probability at site. They are calculated from shape $(k)$ and scale $(c)$ parameters given in Table 1 . Density histograms of monthwise measured wind speed frequency at hub height are also shown in each figure for comparison. A density histogram is a histogram that has been normalized, so it will integrate to one (Martinez and Martinez 2002).

It can be observed from Figure 9a-l that probability curves using graphical method are not fitting the measured wind speed frequency density histograms. Weibull probabilities calculated from empirical, modified maximum likelihood, and energy pattern factor methods are nearly similar and overlapping each other. They are also representing better fit with the density histograms of measured wind speed frequency.

\section{Statistical analysis of four numerical methods}

Table 2 gives the comparison of root mean square errors (RMSEs) of wind speed probabilities and is calculated using monthly Weibull parameters estimated from four methods at hub height. It is observed that modified maximum likelihood method has the lowest and graphical method has highest value for 1-year average monthly RMSE at Soda site. Thus, modified maximum likelihood method gives better results in calculating Weibull function parameters amongst the graphical, empirical, modified maximum likelihood, and energy pattern factor methods at Soda site.
Empirical and EPF methods have almost the same monthly RMSE.

\section{Eighth-degree polynomial fit to wind turbine power curve} data

Power curve data of Suzlon S66-1.25-MW pitchregulated wind turbine (http://www.wind-power-program. com/download.htm. Accessed 09 September 2014; I-Rivera et al. 2009) between cut-in and rated wind speeds are shown in Table 3. Polynomial of eighth degree

$$
\begin{gathered}
P(x)=a_{0}+a_{1} x+a_{2} x^{2}+a_{3} x^{3}+a_{4} x^{4}+a_{5} x^{5} \\
+a_{6} x^{6}+a_{7} x^{7}+a_{8} x^{8}
\end{gathered}
$$

is used to fit the data given in Table 3. Linear least square method and QR decomposition using Gram-Schmidt orthogonalization are used for calculating coefficients of polynomial using MATLAB. Coefficients of eighthdegree polynomial after calculations are in Table 4.

Figure 10 shows the eighth-degree polynomial curve and manufacturer's power curve data of Suzlon S66 wind turbine between cut-in and rated wind speeds. It can be observed that actual data and eighth-degree polynomial model both fit each other.

\section{Measured data of wind turbine- 9 at Soda}

Various measured parameters of wind turbine- 9 from April 2012 to March 2013 are given in Table 5. Wind turbine- 9 data are used for comparison because measurement mast and turbine- 9 are located near to each other as shown in Figure 2. So, it is a reasonably good assumption that turbine- 9 and measurement mast will have the same wind availability.

\section{Table 4 Coefficients of eighth-degree polynomial fit}

\begin{tabular}{ll}
\hline Coefficients & Values \\
\hline$a_{0}$ & 7.2789524 \\
$a_{1}$ & -9.0732954 \\
$a_{2}$ & 4.6960724 \\
$a_{3}$ & -1.3208640 \\
$a_{4}$ & 0.22157098 \\
$a_{5}$ & -0.0227409 \\
$a_{6}$ & 0.0014020 \\
$a_{7}$ & -0.0000477 \\
$a_{8}$ & 0.000000689 \\
\hline
\end{tabular}




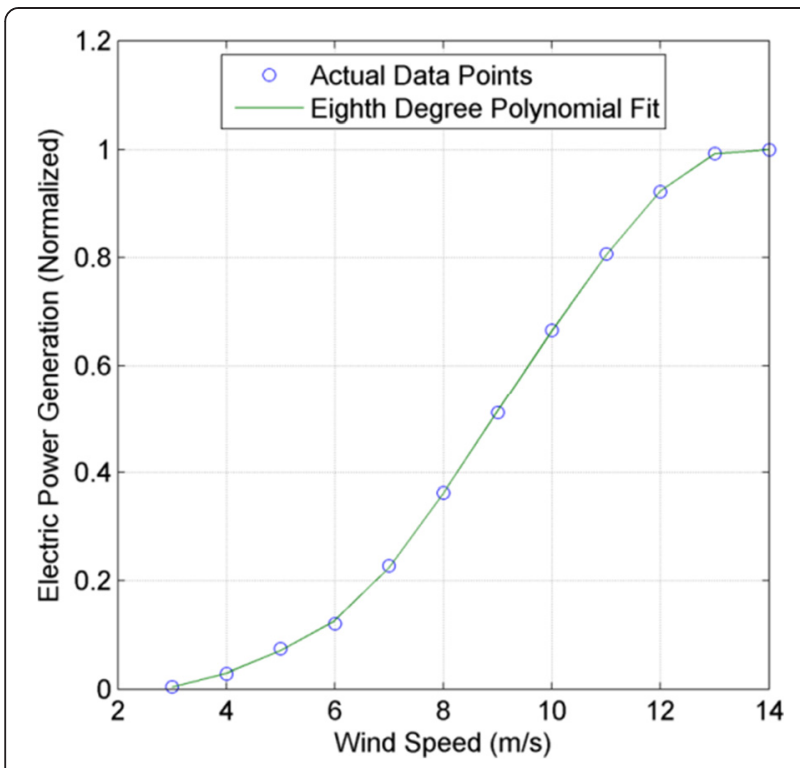

Figure 10 Eighth-degree polynomial fit to Suzlon S66 power curve between cut-in and rated wind speed.

\section{Energy yield losses}

Analytically, estimated values of monthly capacity factor are to be corrected for machine non-availability, grid nonavailability, air density losses, and wake effect losses. The estimated monthly capacity factor values are multiplied by measured monthly machine availability and monthly grid availability given in Table 5 for adjusting the losses associated with machine non-availability and grid nonavailability. The wake effect losses are assumed as 5\% because the wind farm has turbines working in front of the other as shown in Figure 2 and so the estimated monthly capacity factor is multiplied by a factor of 0.95 .

Table 5 Measured data of wind turbine-9 working at Soda wind farm

\begin{tabular}{lllll}
\hline Months & $\begin{array}{l}\text { Energy produced } \\
\text { (kWh) }\end{array}$ & $\begin{array}{l}\text { Capacity } \\
\text { factor }\end{array}$ & $\begin{array}{l}\text { Machine } \\
\text { availability }\end{array}$ & $\begin{array}{l}\text { Grid } \\
\text { availability }\end{array}$ \\
\hline Apr 2012 & 144,798 & 0.1609 & 0.9905 & 0.9826 \\
May 2012 & 214,178 & 0.2303 & 0.9517 & 0.9516 \\
Jun 2012 & 391,530 & 0.4350 & 0.8541 & 0.9813 \\
Jul 2012 & 315,257 & 0.3390 & 0.8025 & 0.9606 \\
Aug 2012 & 203,584 & 0.2189 & 0.977 & 0.9915 \\
Sep 2012 & 94,305 & 0.1048 & 0.9965 & 0.9999 \\
Oct 2012 & 44,503 & 0.0479 & 0.9701 & 0.993 \\
Nov 2012 & 33,257 & 0.0370 & 0.9847 & 0.9932 \\
Dec 2012 & 97,878 & 0.1052 & 0.9942 & 0.9952 \\
Jan 2013 & 48,108 & 0.0517 & 1.0 & 0.9785 \\
Feb 2013 & 94,453 & 0.1124 & 0.9891 & 0.992 \\
Mar 2013 & 107,679 & 0.1158 & 0.9813 & 0.9784 \\
Annual & $1,789,530$ & 0.1634 & 0.9576 & 0.9831 \\
\hline
\end{tabular}

Table 6 Monthly mean air density and correction factor for density at Soda

\begin{tabular}{lll}
\hline Months & $\begin{array}{l}\text { Monthly mean air } \\
\text { density }\left(\mathbf{k g} / \mathbf{m}^{3}\right)\end{array}$ & $\begin{array}{l}\text { Ratio of monthly mean air density } \\
\text { and standard air density }\end{array}$ \\
\hline Apr & 1.106 & 0.903 \\
May & 1.093 & 0.892 \\
Jun & 1.086 & 0.887 \\
Jul & 1.092 & 0.891 \\
Aug & 1.099 & 0.897 \\
Sep & 1.11 & 0.906 \\
Oct & 1.113 & 0.909 \\
Nov & 1.125 & 0.918 \\
Dec & 1.152 & 0.940 \\
Jan & 1.164 & 0.950 \\
Feb & 1.156 & 0.944 \\
Mar & 1.122 & 0.916 \\
Average & 1.118 & 0.913 \\
\hline
\end{tabular}

Suzlon S66 wind turbine has rated wind speed of $14 \mathrm{~m} / \mathrm{s}$. It is evident from Figure 7 that monthly mean wind speed at hub height is always less that $9.09 \mathrm{~m} / \mathrm{s}$ during all the months. The Figure 9a-l shows that wind speed never reached $14 \mathrm{~m} / \mathrm{s}$ during August to February months at Soda site. Moreover, the probability of wind speed occurrence at values equal to or more than $14 \mathrm{~m} / \mathrm{s}$ during March to July period is very low. So, it can be concluded that wind turbines installed at the wind farm are operating below their rated wind speed for most of the time. Majority of the energy production is from ascending section of power curve, which is between cut-in and rated wind speed region. This conclusion is used in calculating the air density correction factor. Estimated monthly capacity factor is

Table 7 Monthly correction factors of estimated capacity factors

\begin{tabular}{ll}
\hline Months & Monthly correction factor \\
\hline Apr & 0.8348 \\
May & 0.7676 \\
Jun & 0.7059 \\
Jul & 0.6528 \\
Aug & 0.8256 \\
Sep & 0.8577 \\
Oct & 0.8315 \\
Nov & 0.8533 \\
Dec & 0.8839 \\
Jan & 0.8833 \\
Feb & 0.8796 \\
Mar & 0.8354 \\
Average & 0.8176 \\
\hline
\end{tabular}


Table 8 Monthly capacity factors estimated using four numerical methods

\begin{tabular}{lllll}
\hline Months & $\begin{array}{l}\text { Estimated } \\
\mathbf{C F}_{\mathbf{m}}(\mathbf{G M})\end{array}$ & $\begin{array}{l}\text { Estimated } \\
\mathbf{C F}_{\mathbf{m}}(\mathrm{EM})\end{array}$ & $\begin{array}{l}\text { Estimated } \\
\mathbf{C F}_{\mathbf{m}}(\mathbf{M M L})\end{array}$ & $\begin{array}{l}\text { Estimated } \\
\mathbf{C F}_{\mathbf{m}}(\mathbf{E P F})\end{array}$ \\
\hline Apr & 0.1598 & 0.1919 & 0.1905 & 0.1913 \\
May & 0.4094 & 0.4465 & 0.4373 & 0.4465 \\
Jun & 0.4467 & 0.5149 & 0.5122 & 0.5139 \\
Jul & 0.3039 & 0.3363 & 0.3329 & 0.3373 \\
Aug & 0.1600 & 0.1910 & 0.1880 & 0.1894 \\
Sep & 0.1862 & 0.1969 & 0.1930 & 0.2003 \\
Oct & 0.1001 & 0.1189 & 0.1222 & 0.1167 \\
Nov & 0.0415 & 0.0476 & 0.0501 & 0.0453 \\
Dec & 0.0896 & 0.0966 & 0.0991 & 0.0937 \\
Jan & 0.0870 & 0.0976 & 0.0991 & 0.0957 \\
Feb & 0.1149 & 0.1308 & 0.1312 & 0.1303 \\
Mar & 0.1604 & 0.1810 & 0.1824 & 0.1818 \\
\hline
\end{tabular}

corrected by multiplying it with the ratio of monthly mean air density at site to standard air density of $1.225 \mathrm{~kg} / \mathrm{m}^{3}$. The values of ratio are given in Table 6 (Hau 2006). This correction process also takes care of the differences in air density between summer (May, June) and winter (December, January) seasons.

\section{Comparison of measured and corrected estimated capacity factors}

Monthly correction factors by considering machine nonavailability, grid non-availability, air density losses, and wake effect losses are given in Table 7 . Table 8 shows the estimated monthly capacity factor values. They are calculated using Equation 35 and data given in Tables 1 and 4. Table 9 shows the corrected monthly capacity factors. Corrected monthly capacity factors are obtained by multiplying the

Table 9 Corrected capacity factors estimated using four numerical methods

\begin{tabular}{lllll}
\hline Months & $\begin{array}{lll}\text { Corrected } \\
\mathbf{C F}_{\mathbf{m}}(\mathbf{G M})\end{array}$ & $\begin{array}{l}\text { Corrected } \\
\mathbf{C F}_{\mathbf{m}}(\mathbf{E M})\end{array}$ & $\begin{array}{l}\text { Corrected } \\
\mathbf{C F}_{\mathbf{m}}(\mathbf{M M L})\end{array}$ & $\begin{array}{l}\text { Corrected } \\
\mathbf{C F}_{\mathbf{m}} \text { (EPF) }\end{array}$ \\
\hline Apr & 0.1334 & 0.1602 & 0.1590 & 0.1597 \\
May & 0.3143 & 0.3428 & 0.3357 & 0.3428 \\
Jun & 0.3153 & 0.3635 & 0.3615 & 0.3627 \\
Jul & 0.1984 & 0.2195 & 0.2173 & 0.2202 \\
Aug & 0.1321 & 0.1577 & 0.1552 & 0.1564 \\
Sep & 0.1597 & 0.1689 & 0.1655 & 0.1718 \\
Oct & 0.0832 & 0.0989 & 0.1016 & 0.0970 \\
Nov & 0.0354 & 0.0406 & 0.0427 & 0.0387 \\
Dec & 0.0792 & 0.0854 & 0.0876 & 0.0828 \\
Jan & 0.0768 & 0.0862 & 0.0875 & 0.0845 \\
Feb & 0.1011 & 0.1151 & 0.1154 & 0.1146 \\
Mar & 0.1340 & 0.1512 & 0.1524 & 0.1519 \\
\hline
\end{tabular}

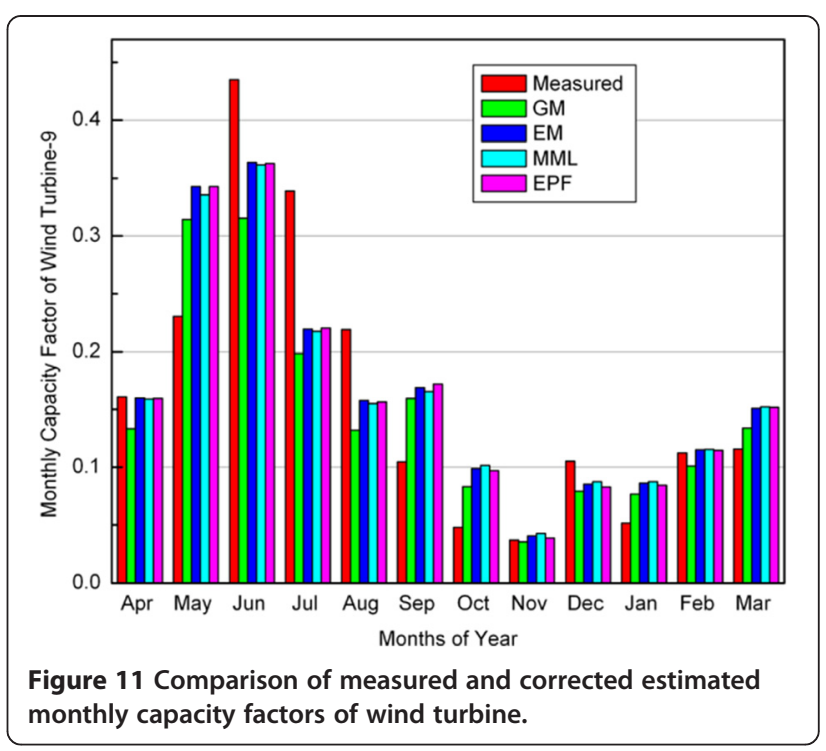

estimated monthly capacitor factors given in Table 8 with the monthly correction factors given in Table 7. It is to be noted that measured wind speed frequency distribution data are from April 2011 to March 2012 whereas measured wind turbine-9 energy production data are from April 2012 to March 2013. Comparison between the measured and corrected values of capacity factor are done assuming that the wind profile of a site does not change significantly from 1 year to another year.

Figure 11 shows the graphical comparison of measured and corrected monthly capacity factor values given in Tables 5 and 9, respectively.

Corrected monthly capacity factors shown in Table 9 does not give a comprehensible result, as monthly wind profile may vary from 1 year to another year. So, corrected annual capacity factor of wind turbine are calculated and then the percentage errors between the measured and corrected values of annual capacity factor are obtained as shown in Table 10. It is observed that percentage error in annual capacity factor computation by using Weibull parameters estimated from MML method is $-1.22 \%$. It is the lowest in comparison to graphical, empirical, and energy pattern factor methods. Graphical method gave the most erroneous results.

Table 10 Comparison between corrected annual capacity factors along with percentage error

\begin{tabular}{lll}
\hline $\begin{array}{l}\text { Methods of } \\
\text { estimating } \\
\begin{array}{l}\text { Weibull } \\
\text { parameters }\end{array}\end{array}$ & $\begin{array}{l}\text { Corrected annual } \\
\text { capacity factor }\end{array}$ & $\begin{array}{l}\text { Percentage error (comparing } \\
\text { with wind turbine-9 measured } \\
\text { annual CF of 0.1634) (\%) }\end{array}$ \\
\hline GM & 0.1471 & +9.98 \\
EM & 0.1660 & -1.59 \\
MML & 0.1654 & -1.22 \\
EPF & 0.1655 & -1.29 \\
\hline
\end{tabular}




\section{Conclusions}

This paper analyzed wind characteristics, Weibull wind speed distribution using four numerical methods, eighthdegree polynomial modeling of wind turbine power curve, and capacity factor estimation of wind turbines at Soda site in the desert region of western Rajasthan in India. The percentage error in annual capacity factor estimation using Weibull parameters estimated from graphical, empirical, modified maximum likelihood, and energy pattern factor methods were $+9.98 \%,-1.59 \%,-1.22 \%$, and $-1.29 \%$, respectively. Annual capacity factors calculated using Weibull parameters estimated from modified maximum likelihood method matched the measured values best and the graphical method gave the most erroneous results. Wind power density is highest in June and lowest in November with measured values of $568.45 \mathrm{~W} / \mathrm{m}^{2}$ and $49.03 \mathrm{~W} / \mathrm{m}^{2}$, respectively. It shows a large variation due to change in monthly weather conditions.

\section{Abbreviations \\ WPD: wind power density; RMSE: root mean square error; GM: graphical method; EM: empirical method; MML: modified maximum likelihood; EPF: energy pattern factor; CF: capacity factor.}

\section{Competing interests}

The authors declare that they have no competing interests.

\section{Authors' contribution}

BKS carried out the data acquisition, analysis, and interpretation and drafted the manuscript. KVSR contributed in the conception and designing of case study, data analysis, and critical review of the manuscript. Both authors read and approved the final manuscript.

\section{Authors' information}

BKS is M.Tech. (Renewable Energy Technology) research student of the Centre for Energy and Environment at Rajasthan Technical University, Kota, India. He obtained Bachelors degree in Electrical Engineering from Engineering College, Kota. KVSR is professor in Mechanical Engineering and presently head of the Centre for Energy and Environment at Rajasthan Technical University, Kota. He is also M.Tech. dissertation supervisor of BKS. KVSR obtained Bachelors degree in Mechanical Engineering from NIT Jamshedpur, Masters degree in Mechanical Engineering from ITT Kanpur, and Ph.D. degree from ITT Delhi.

\section{Acknowledgements}

The authors would like to thank Rajasthan Renewable Energy Corporation Limited at Jaipur and Suzlon Energy Limited at Jaisalmer for granting permissions to visit their wind farm and providing requisite data for analysis.

Received: 11 September 2014 Accepted: 7 October 2014

Published online: 20 January 2015

\section{References}

Albadi, M. H. (2010). On techno-economic evaluation of wind-based DG. In PhD thesis. Waterloo, Ontario: Dept. Electrical and Computer Engineering, University of Waterloo.

Albadi, M. H., \& El-Saadany, E. F. (2009). Wind turbine capacity factor modeling: a novel approach. IEEE Transactions on Power Systems, 24(3), 1637-1638.

Albadi, M. H., \& El-Saadany, E. F. (2012). Comparative study on impacts of power curve model on capacity factor estimation of pitch-regulated turbines. The Journal of Engineering Research, 9(2), 36-45.

Bird, J. (2003). Engineering mathematics. Oxford: Newnes.

Centre for Wind Energy Technology. (2011). Course Material: Seventh international training course on wind turbine technology and applications from Aug. 3-26, 2011. Chennai: C-WET
Chang, T.-J., \& Tu, Y.-L. (2007). Evaluation of monthly capacity factor of WECS using chronological and probabilistic wind speed data: a case study of Taiwan. Renewable Energy, 32(12), 1999-2010.

Chang, T.-J., Wu, Y.-T., Hsu, H.-Y., Chu, C.-R., \& Liao, C.-M. (2003). Assessment of wind characteristics and wind turbine characteristics in Taiwan. Renewable Energy, 28(6), 851-871.

Demmel, J. W. (1997). Applied numerical linear algebra. Philadelphia: SIAM.

Ditkovich, Y., Kuperman, A., Yahalom, A., \& Byalsky, M. (2012). A generalized approach to estimating capacity factor of fixed speed wind turbines. IEEE Transactions on Sustainable Energy, 3(3), 607-608.

EL-Shimy, M. (2010). Optimal site matching of wind turbine generator: case study of the Gulf of Suez region in Egypt. Renewable Energy, 35(8), 1870-1878.

Embree, M. (2010). Lecture notes: CAAM 453 Numerical Analysis-1 Rice University. http:// www.caam.rice.edu/ caam553/caam453.pdf. Accessed 09 September 2014.

Hau, E. (2006). Wind Turbines: fundamentals, technologies, application, economics. Berlin: Springer-Verlag.

Hu, S. Y., \& Cheng, J. H. (2007). Performance evaluation of pairing between sites and wind turbines. Renewable Energy, 32(11), 1934-1947.

Huang, S.-J., \& Wan, H.-H. (2011). A modular approach to enhance capacity factor computation of wind turbine generators. IEEE Transactions on Energy Conversion, 26(3), 987-989.

Huang, S.-J., \& Wan, H.-H. (2012). Determination of suitability between wind turbine generators and sites including power density and capacity factor considerations. IEEE Transactions on Sustainable Energy, 3(3), 390-397.

I-Rivera, A. A., C-Rios, J. A., \& N-Carrillo, E. O. (2009). Achievable renewable energy targets for Puerto Rico's renewable energy portfolio standard: Final report. http://www.uprm.edu/aret/. Accessed 09 September 2014.

Jangamshetti, S. H., \& Rau, V. G. (1999). Site matching of wind turbine generators: a case study. IEEE Transactions on Energy Conversion, 14(4), 1537-1543.

Jangamshetti, S. H., \& Rau, V. G. (2001). Normalized power curves as a tool for identification of optimum wind turbine generator parameters. IEEE Transactions on Energy Conversion, 16(3), 283-288.

Johnson, G. L. (1978). Economic design of wind electric systems. IEEE Transactions on Power Apparatus and Systems, 97(2), 554-562.

Jowder, F. A. L. (2009). Wind power analysis and site matching of wind turbine generators in Kingdom of Bahrain. Applied Energy, 86(4), 538-545.

Manwell, J. F., McGowan, J. G., \& Rogers, A. L. (2009). Wind energy explained: theory, design and application. West Sussex: Wiley.

Martinez, W. L., \& Martinez, A. R. (2002). Computational statistics handbook with MATLAB. Boca Raton: Chapman \& Hall/CRC.

Masters, G. M. (2004). Renewable and efficient electric power systems. Hoboken: Wiley.

Press, W. H., Teukolsky, S. A., Vetterling, W. T., \& Flannery, B. P. (2009). Numerical recipes in C: the art of scientific computing. New Delhi: Cambridge University Press.

Rehman, S., \& Ahmad, A. (2004). Assessment of wind energy potential for coastal locations of the Kingdom of Saudi Arabia. Energy, 29(8), 1105-1115.

Rocha, P. A. C., de Sousa, R. C., de Andrade, C. F., \& da Silva, M. E. V. (2012). Comparison of seven numerical methods for determining Weibull parameters for wind energy generation in the northeast region of Brazil. Applied Energy, 89(1), 395-400.

Suzlon Energy Ltd. S66-1.25 MW Technical Overview. http://www.suzlon.com/pdf/ s66\%20product\%20brochure.pdf. Accessed 09 September 2014.

The MathWorks Inc. Orthogonal-triangular decomposition-MATLAB qr. http://in. mathworks.com/help/matlab/ref/qr.html. Accessed 09 September 2014.

Wind Power Program. Wind turbine power curve database. http://www.windpower-program.com/download.htm. Accessed 09 September 2014.

\section{Submit your manuscript to a SpringerOpen ${ }^{\odot}$ journal and benefit from:}

- Convenient online submission

Rigorous peer review

- Immediate publication on acceptance

- Open access: articles freely available online

- High visibility within the field

- Retaining the copyright to your article

Submit your next manuscript at $\gg$ springeropen.com 